\title{
Sero Status Disclosure to Sexual Partner and Associated Factors among Adult HIV Positive Patients in Bale Zone Hospitals, Oromia Region, Ethiopia: Institution Based Cross-Sectional Study
}

\author{
Tsige Defere Geremew1, Rameto Aman Nuri2 ${ }^{*}$, Jeylan Kassim Esmael2 \\ ${ }^{1}$ Bale Zone, Goba Town Health Office, Bale Goba, Ethiopia \\ ${ }^{2}$ Department of Public Health, Goba Referral Hospital, Madda Walabu University, Bale Goba, Ethiopia \\ Email: tsigedefere@gmail.com, ‘rametoaman@gmail.com, jeylan.nadir@gmail.com
}

How to cite this paper: Geremew, T.D., Nuri, R.A. and Esmael, J.K. (2018) Sero Status Disclosure to Sexual Partner and Associated Factors among Adult HIV Positive Patients in Bale Zone Hospitals, Oromia Region, Ethiopia: Institution Based Cross-Sectional Study. Open Journal of Epidemiology, 8, 43-53.

https://doi.org/10.4236/ojepi.2018.82004

Received: January 13, 2018

Accepted: May 8, 2018

Published: May 11, 2018

Copyright $\odot 2018$ by authors and Scientific Research Publishing Inc. This work is licensed under the Creative Commons Attribution International License (CC BY 4.0). http://creativecommons.org/licenses/by/4.0/

\section{Open Access}

\begin{abstract}
Background: Disclosure of HIV sero status is among varies HIV prevention strategy to prevent the spread of HIV. It is the base for accessing care and treatment programs, attains psycho-social support and reduces stigma, adheres to treatment and promotes safer health behavior particularly for couples. Objective: To assess HIV sero status disclosure to sexual partner and associated factors among HIV positive adult patient in Bale Zone hospitals. Method: A cross-sectional study design was conducted among 411 adult HIV positive clients who were selected by using systematic random sampling methods from Bale Zone Hospitals. Data were collected by using pre-tested questionnaire after verbal consent obtained from participants by trained nurse. Multiple logistic regression analysis was done by using SPSS version 20 and P-value of less than 0.05 was taken to declare statistical significance. Result: HIV sero status disclosure to sexual partners was $52.6 \%$. Residence (AOR $=1.62 ; 95 \% \mathrm{CI}, 1.0,2.60$ ), receiving pre-test counselling related disclosure $(\mathrm{AOR}=6.25 ; 95 \% \mathrm{CI}, 3.45,11.33)$ and knowledge of partner's HIV sero status $(\mathrm{P}$-Value $=0.001)$ were significantly associated with HIV sero status disclosure. Fear of stigma and violence by sexual partner were the main reasons suggested for not disclosing HIV sero-status. Conclusion: The level of HIV sero-status disclosure to sexual partner was low. Disclosure of HIV sero status to sexual partner was significantly associated with clients' place of residence, receiving pre-test counselling about disclosure and Knowledge of partners HIV sero status.
\end{abstract}




\section{Keywords}

HIV Sero Status, Disclosure, Sexual Partner, Adult Clients

\section{Introduction}

Human immune deficiency virus continues to be a major public health problem particularly in Sub-Saharan Africa where more than ten million people were living with the virus of which 960,000 were newly infected. With regard to antiretroviral therapy (ART) service success, only $26 \%$ of decline in AIDS related death was attributable to the service. In Ethiopia, the number of people with new infection was 21,216 and about $32.9 \%$ of them belong to the age group of $15-24$ years. The total number of death at the same time due to acquired Immunodeficiency Syndrome (AIDS) was 16,865 from the total cases. The prevalence of HIV/AIDS in Oromia regional state was estimated to be $0.89 \%$ [1]. Disclosure of HIV sero status to sexual partners plays a vital role in the prevention and control of HIV/AIDS. Considering that, great emphasis has been given for HIV sero status disclosure in the protocols of HIV counseling and testing by various stakeholders. It was known to offer numerous benefits to HIV positive clients as well as to the larger community. Disclosure of HIV sero status to sexual partners can minimize anxiety developed secondary to the infection and possibly improve social support from sexual partner [2] [3]. Various study conducted to assess the magnitude of HIV sero status disclosure in different setting and population have shown different level of disclosure status. The negative outcome of HIV sero status was known to be major challenges in HIV/AIDS prevention and control strategies since it is affected by numerous factors. Studies conducted in developing countries particularly in sub-Saharan Africa showed that, disclosure level of ranging from $16.7 \%$ to $86 \%$ [4]. Disclosure level of $56.3 \%$ was documented by the study conducted at Kisarawe District Hospital of Tanzania. Sex of HIV positive client and receiving pre-test counselling service related to disclosure were identified as significant determinants of HIV sero status disclosure to sexual partner [5]. Based on the study done on HIV positive pregnant Women on lifelong antiretroviral therapy at Uganda, Nearly three fourth of the study participants $(73.3 \%)$ had disclosed to their sexual partner. Better disclosure has been seen among study participants who reported as they get partner support for either antenatal care or HIV-related care services [6]. Another research done in a secondary health facility of North-Eastern Nigeria showed a prevalence of HIV sero status disclosure to spouse of $36.8 \%$ and age of the respondents was found to be significantly associated with sero status disclosure [7].

A cross sectional study done in Kenya, Nambia and Tanzania revelead, HIV sero status disclosure of $90.8 \%$ [8]. Disclosure of HIV sero status to sexual partner of $60.9 \%$ was documented by the research done at Sokodé regional hospital of Togo and nearly all of the participants who disclosed their HIV sero status 
have knowledge of their sexual partner HIV sero status [9]. In Ethiopia, different level of sero status disclosure was documented. The study done at Axum health facility showed $41.8 \%$ level of sero status disclosure to sexual partner. The main reasons for non-disclosure were fear of stigma and rejection, fear of breach of confidentiality, fear of divorce and fear of accusation of infidelity. Marital status of the respondents, knowledge of partner's HIV status and being a member of Anti-HIV/AIDS association were identified as significant determinants of sero status disclosure [10]. The studies done at Jimma University Specialized Hospital, kemisse health center, Hawassa Referral Hospital and Woldia hospital revelead $90.2 \%, 93.1 \%, 92.2 \%$ and $76.6 \%$ level of HIV sero status disclosure to sexual partner respectively [10] [11] [12] [13]. Pre-test discussion about the benefit of sero status disclosure and knowing their partner's HIV sero status were significantly associated with HIV sero status disclosure to sexual partners [12] [13] [14]. A cross sectional study done at Mekelle Hospital among patients attending antiretroviral treatment clinic follow up revelead overall HIV status disclosure to sexual partner of $57.4 \%$. The study showed that there was significant association between knowing HIV status of sexual partner, duration of HIV related care follow up and discussion before HIV testing with HIV positive status disclosure to sexual partner [15]. This study tried to assess HIV sero status disclosure to sexual partners and identify context based influencing factor for sero status disclosure to sexual partner. So that, finding of this study have a great role in contributing valuable information about HIV positive status disclosure to sexual partner and it provides scientific evidence regarding the factors which influence a person's decision to disclose his/her HIV sero status to sexual partner which help policy makers, health planners and health workers to devise effective strategy for improving HIV sero status disclosure so as to benefit from it as vital protocol for HIV prevention and control strategies.

\section{Methods and Materials}

\subsection{Study Area and Period}

The study was conducted in Bale zone hospitals. Bale is one of the zones located in the South Eastern part of Oromia regional state. Based on central statistical agency (CSA) projection of Bale zone branch office, the current total population of the zone in 2016 was 1,807,278 [16]. Regarding the health system of the zone, there are 4 functional hospitals namely Goba referral, Bale Robe, Ginnir and Dello Menna hospital, 84 health centers, 327 health posts and 34 private clinics. All hospitals provide HIV/AIDS care and treatment services. Based on the Zonal health management information (HMIS) report, there were total of 862, 1708, 651 population using care and treatment service for HIV/AIDS in addition to voluntary counselling and testing, prevention of mother to child transmission and treatment of opportunistic infection [17]. Field data collection was done from May 1 to 30, 2017 at each hospital. 


\subsection{Study Design}

Facility based cross-sectional study design was conducted among HIV positive adults clients attending care and treatment centers of Bale Zone Hospitals.

\subsection{Source Population}

The source population of the study was all of HIV positive adult clients who have sexual partner and attend care and treatment centers of Bale Zone Hospitals.

\subsection{Study Population}

All adult clients who have sexual partner and attending clinical care and treatment center for HIV/AIDS during data collection period that fulfil the inclusion criteria in Bale Zone Hospitals.

\subsection{Inclusion and Exclusion Criteria}

Adult age greater than and equal to 18 years who have sexual partner before data collection and attending care and treatment for HIV/AIDS at Bale zone hospitals were included. Adult clients who were mentally ill and unable to hear were excluded from the study.

\subsection{Sample Size Determination}

Sample size was determined by using single population proportion formula with the following assumptions:

$n=$ the desired sample size

$p=$ proportion of inpatients service satisfaction which is $41.8 \%$ [9].

$\mathrm{Z} \alpha / 2=$ critical value for normal distribution at $95 \%$ confidence level which is equal to 1.96 ( $\mathrm{z}$ value at $=0.05$ )

$d=$ the margin of error taken as $5 \%$

Then,

$$
\begin{gathered}
n=\frac{(Z \alpha / 2)^{2} p(1-p)}{d^{2}} \\
n=\frac{(1.96)^{2} 0.418(1-0.418)}{(0.05)^{2}}=374
\end{gathered}
$$

Therefore, adding 10\% for possible non rate, the total sample size was 411 .

\subsection{Sampling Procedure}

Based on the total number of adult HIV positive patients who have sexual partner and attending regular follow up for clinical care flow at 2016 of each hospital, the sample was proportionally allocated to each hospital accordingly. Systematic random sampling method was used to select illegible participants from each ART unit. Every $8^{\text {th }}$ HIV positive adult who came for care and treatment was selected. When both sexual partners came to care and treatment center during data collection period, lottery method was used to select one of the partner. 


\subsection{Data Collection Procedure}

Face to face interview data collection method was used to collect the data using structured and pretested questionnaire which was developed by referring similar literatures. The questionnaire was translated into Amharic and Afan Oromo language which are the local languages. Four nurses who were working in ART and counseling clinic from each hospital were involved in the pre-testing of the data collection tool and actual data collection after taking training and verbal consent from study participants.

\subsection{Data Quality Control}

The questionnaire was developed in English and translated in to Amharic and Afan Oromo (the local languages) and back translated to English to ensure its consistency. The questionnaire was pre-tested on $5 \%$ of the sample size at Dodola Hospital and necessary modifications were made accordingly. Data collectors were trained for one day before the data collection period by investigator on objective of the research, data collection tool and ethical issues. Strict supervision and follow-up of data collection process were made by the investigators.

\subsection{Data Processing and Analysis}

The collected data were cross-checked, entered, cleaned and analysed using SPSS version 20 statistical package. Descriptive statistical analysis was done for socio-demographic characteristics of the respondents and to determine the level of HIV sero status disclosure to sexual partner among ART clients. Multiple binary logistic regression analysis was done to identify factors associated with HIV sero status disclosure to sexual partner. Statistical significance and strength of association between HIV sero status disclosure to sexual partner and various independent variables were measured on the basis of adjusted odds ratio and the cross ponding $\mathrm{P}$-value. Statistical significance was declared at P-value of less than 0.05 .

\subsection{Ethical Consideration}

Ethical approval was obtained from Madda Walabu University, Goba Referral Hospital, Public Health Departmental Graduating Committee. Permission letter was given for Bale Zone Health office and each hospital. The purpose of the study was explained to study participants and verbal consent was taken. The participation in the study was entirely voluntary and confidentiality was secured through assigning code instead of personal identifiers. The rights of participants to continue or withdraw to participate at any time during the interview were respected.

\section{Results}

\subsection{Socio Demographic and Economic Related Characteristics of Study Participants}

A total of 411 adult HIV sero positive clients were involved in the study making 
a response rate of $100 \%$. The mean age of respondents was 36.57 with standard deviation of 8.59 years. More than half of the respondents (52.8\%) were female. Regarding place of residence, 262 (63.7\%) of the respondents were urban dwellers. About $175(42.6 \%)$ of the respondents attended primary school education. Concerning occupation, 152 (37\%) of the participants were farmer and 156 (38\%) of the respondents had an average monthly income of more than or equal to 1000 Ethiopian Birr (Table 1).

\subsection{HIV and Health Care Related Characteristics of Clients}

In this study, about $313(76.2 \%)$ of participants were received pre-test counselling with regard sero status disclosure. Nearly quarter of the study participants has known their HIV sero status three back and 186 (45.3\%) of them tested for HIV due to illness (Table 2, Figure 1).

The main reason for non-disclosure of HIV sero status to sexual partner, fear of stigma and discrimination (36.9\%) followed by Fear of partner violence (27.7\%) (Figure 2).

\subsection{Factors Associated with HIV Sero Status Disclosure to Sexual Partners}

Based on multiple binary logistic regression analysis, place of residence, counselling related to disclosure and knowledge of partners HIV sero status were significantly associated with HIV-sero status disclosure to sexual partner. Accordingly, clients' living in urban area were nearly two times more likely to disclose their HIV sero status to their sexual partner as compared to rural dwellers (AOR $=1.62 ; 95 \%$ CI, 1.01, 2.60). The odds of disclosing HIV sero status to sexual partner were six times higher among participants who received pre-test counselling related to disclosure compared with their counterpart $(\mathrm{AOR}=6.25 ; 95 \% \mathrm{CI}$, $3.45,11.33)$. Knowing partner HIV sero status was positively associated with sero status disclosure. Respondents who knew their sexual partner's HIV status were about four times more likely to disclose their HIV sero status to their partner as compared to those who did not know their partner's HIV sero status $(\mathrm{AOR}=4.16 ; 95 \% \mathrm{CI}=2.54,6.81, \mathrm{P}$-value $=0.001)($ Table 3$)$.

\section{Discussion}

This study has been conducted with the aim of assessing the magnitude and factors associated with HIV sero status disclosure to sexual partners. Accordingly, the magnitude of HIV sero status disclosure to sexual partner among the study participants was $52.6 \%$. The finding is lower when compared with study conducted at of Jimma University specialized hospital(90.8\%), Hawasa referral Hospital (85.7\%), at ART clinic of Mekelle hospital Northern part of Ethiopia (63.8\%) [11] [13] \& [18]. The possible reason could be Jimma University specialized hospital, Hawasa referral Hospital and Mekelle hospitals are higher level hospitals where adult HIV sero positive clients from such hospitals possibly obtain better HIV related services which in turn promote them to disclose their 
Table 1. Socio demographic characteristics of adult HIV positive patient at Hospital of Bale Zone, Oromia Regional Stat, Ethiopia, 2017 ( $\mathrm{n}=411)$.

\begin{tabular}{|c|c|c|c|}
\hline Characteristics & Category & Frequency & Per cent \\
\hline \multirow{2}{*}{ Sex } & Male & 194 & 47.2 \\
\hline & Female & 217 & 52.8 \\
\hline \multirow{2}{*}{ Residence } & Urban & 262 & 63.7 \\
\hline & Rural & 149 & 36.3 \\
\hline \multirow{5}{*}{ Age } & $18-24$ & 18 & 4.4 \\
\hline & $25-34$ & 142 & 34.5 \\
\hline & $35-44$ & 181 & 44.0 \\
\hline & $45-54$ & 56 & 13.6 \\
\hline & $\geq 55$ & 14 & 3.4 \\
\hline \multirow{5}{*}{ Religion } & Orthodox & 251 & 61.1 \\
\hline & Muslim & 120 & 29.5 \\
\hline & Catholic & 30 & 7.3 \\
\hline & Protestant & 7 & 1.7 \\
\hline & Other & 3 & 0.7 \\
\hline \multirow{5}{*}{ Marital status } & Never married & 29 & 7.1 \\
\hline & Married & 282 & 68.6 \\
\hline & Separated & 40 & 9.7 \\
\hline & Divorced & 43 & 10.5 \\
\hline & Widowed & 17 & 4.1 \\
\hline \multirow{4}{*}{ Educational status } & Unable to read \& write & 82 & 20 \\
\hline & Primary & 175 & 42.6 \\
\hline & Secondary & 118 & 28.7 \\
\hline & College $\&$ above & 36 & 8.8 \\
\hline \multirow{6}{*}{ Occupation } & Employed & 85 & 20.7 \\
\hline & self employed & 63 & 15.3 \\
\hline & Farmer & 152 & 37.0 \\
\hline & Unemployed & 97 & 23.6 \\
\hline & Student & 2 & 0.5 \\
\hline & Others(types of occupation) & 12 & 3.2 \\
\hline \multirow{4}{*}{ Monthly income } & $<500 \mathrm{~EB}$ & 71 & 17.3 \\
\hline & 501 to $999 \mathrm{~EB}$ & 120 & 29.2 \\
\hline & $\geq 1000 \mathrm{~EB}$ & 156 & 38.0 \\
\hline & Unstated & 64 & 15.6 \\
\hline \multirow{3}{*}{$\begin{array}{l}\text { Number of sexual } \\
\text { partner }\end{array}$} & Only one & 254 & 61.8 \\
\hline & Two & 137 & 33.3 \\
\hline & More than two & 20 & 4.9 \\
\hline
\end{tabular}

HIV sero status to sexual partner. The finding was higher than the result of a study in Axum health facilities Northern part of Ethiopia which revealed over all HIV sero-status disclosure to sexual partner of $41.8 \%$ [10]. This could be 
Table 2. HIV and Health care related characteristics of adult HIV positive patient in Hospitals of Bale Zone, Oromia, Regional State, Ethiopia, 2017.

\begin{tabular}{|c|c|c|c|}
\hline Characteristics & Category & Frequency & Per cent \\
\hline \multirow{6}{*}{$\begin{array}{c}\text { Time to know your HIV sero } \\
\text { status }\end{array}$} & 1 year & 57 & 13.9 \\
\hline & $2-3$ years & 91 & 22.1 \\
\hline & $4-5$ years & 87 & 21.2 \\
\hline & $6-7$ years & 67 & 16.3 \\
\hline & $8-9$ years & 73 & 17.8 \\
\hline & $\geq 10$ years & 36 & 8.8 \\
\hline \multirow{3}{*}{$\begin{array}{l}\text { Received pre-test Counselling } \\
\text { related to disclosure }\end{array}$} & Yes & 313 & 76.2 \\
\hline & No & 98 & 23.8 \\
\hline & Becoming sick & 186 & 45.3 \\
\hline \multirow{5}{*}{ Initiating factor to test for HIV } & Partners/child/illness/death & 43 & 10.6 \\
\hline & Heard on radio/TV & 19 & 4.6 \\
\hline & Health provider recommendation & 116 & 28.2 \\
\hline & Family or friend encouragement & 21 & 5.5 \\
\hline & Self-initiated & 26 & 6.5 \\
\hline \multirow{4}{*}{ Know partners HIV status } & Yes & 281 & 68.4 \\
\hline & No & 130 & 31.6 \\
\hline & 1 to 2 years & 92 & 22.4 \\
\hline & 3 to 5 years & 148 & 36.0 \\
\hline \multirow{4}{*}{ Duration on ART } & 5 to 7 years & 73 & 17.8 \\
\hline & 7 to 10 years & 86 & 20.9 \\
\hline & $>10$ years & 8 & 1.9 \\
\hline & Don't know & 4 & 1.0 \\
\hline
\end{tabular}

Table 3. Factors associated with HIV sero status disclosure to sexual partners among adult HIV positive patients in Hospitals of Bale Zone, Oromia Region, Ethiopia 2017.

\begin{tabular}{|c|c|c|c|c|c|c|}
\hline \multirow{2}{*}{\multicolumn{2}{|c|}{ Characteristic }} & \multicolumn{2}{|c|}{$\begin{array}{c}\text { Disclosure of } \\
\text { HIV status }\end{array}$} & \multirow[t]{2}{*}{ COR (95 \% CI) } & \multirow[t]{2}{*}{$\operatorname{AOR}(95 \% \mathrm{CI})$} & \multirow[t]{2}{*}{ P-Value } \\
\hline & & Yes & No & & & \\
\hline \multirow{2}{*}{ Residence } & Urban & 152 & 110 & $1.83(1.22-2.75)$ & $1.62(1.01-2.60)^{*}$ & 0.042 \\
\hline & Rural & 64 & 85 & 1 & 1 & \\
\hline \multirow{4}{*}{$\begin{array}{c}\text { Educational } \\
\text { Level }\end{array}$} & $\begin{array}{l}\text { Unable } \\
\text { read and } \\
\text { write }\end{array}$ & 32 & 50 & $0.24(0.10-0.57)$ & $0.52(0.19-1.37)$ & \\
\hline & Primary & 82 & 93 & $0.33(0.15-0.74)$ & $0.48(0.20-1.16)$ & \\
\hline & Secondary & 76 & 42 & $0.69(0.30-1.58)$ & $0.78(0.31-1.95)$ & \\
\hline & $\begin{array}{c}\text { College and } \\
\text { above }\end{array}$ & 26 & 10 & 1 & 1 & \\
\hline $\begin{array}{l}\text { Receiving pre-test } \\
\text { counselling }\end{array}$ & Yes & 198 & 18 & $7.65(4.36-13.40)$ & $6.25(3.45-11.33)^{*}$ & 0.001 \\
\hline $\begin{array}{l}\text { related to } \\
\text { disclosure }\end{array}$ & No & 115 & 80 & 1 & 1 & \\
\hline $\begin{array}{l}\text { Knowledge } \\
\text { partners HIV }\end{array}$ & Yes & 180 & 101 & $4.65(2.96-7.33)$ & $4.16(2.54-6.81)^{*}$ & 0.001 \\
\hline sero status & No & 36 & 94 & 1 & 1 & \\
\hline
\end{tabular}




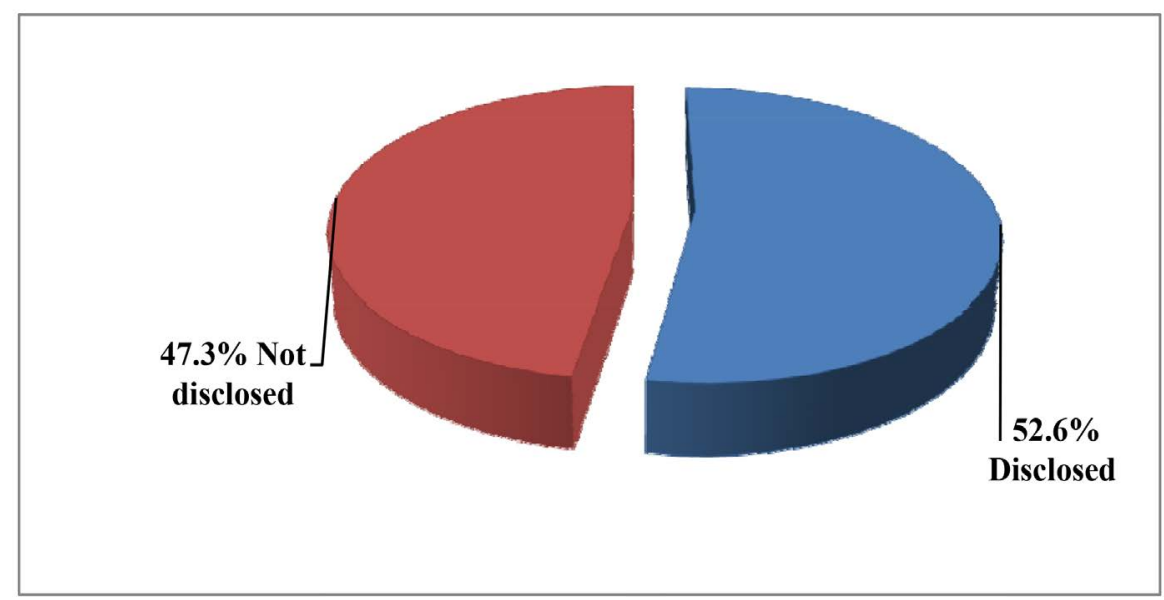

Figure 1. Magnitude of HIV sero status disclosure to sexual partner among adult HIV positive clients at Hospitals of Bale Zone, Oromia Region, Ethiopia, 2017.

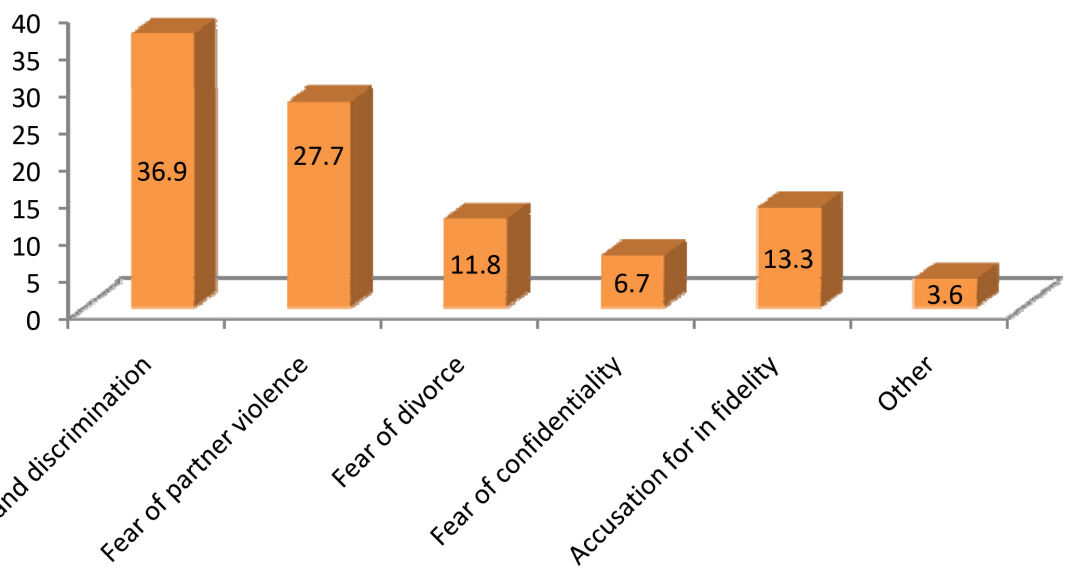

Figure 2. Reason for non-disclosure of HIV sero status to sexual partners among adult HIV positive patients in Hospitals of Bale Zone, Oromia region, Ethiopia, 2017.

attributable to the time gap between the studies, where there is accelerated expansion of the HIV/AIDS service carried out through an increased advocacy which could favour better disclosure in this study. The main reasons for non-disclosure among those study subjects who did not disclosed their HIV sero status to their sexual partner were fear of stigma and discrimination, fear of partner violence, fear of divorce, fear of confidentiality and fear of accusation for in fidelity. It is consistent with the studies carried out elsewhere in Ethiopia [10] [12] [13]. Based on multiple logistic regression analysis, receiving pre-test counselling about HIV sero status disclosure has positive association with HIV sero-status disclosure to sexual partner. Those study participants who received pre-test counselling were six times more likely to disclose their HIV sero status to sexual partner than their counterpart which is in line with the finding of the study conducted at Kemissie Health Center and Woldia hospital [12] [14]. It could be due pre-test counselling has played a significant role in facilitating HIV sero status disclosure to sexual partner. The odds of HIV sero status disclosure 
among adult HIV clients who knew their sexual partner's HIV sero status were nearly four times higher compared with those who did not know their partner's HIV status. The result is supported by study done in Hawasa Referral Hospital, kemissie health center, Woldia hospital, Tanzania, Kenya and Namibia and Sokodé Regional Hospital of Togo [8] [9] [12] [13] and [14].

Knowledge of sexual partners HIV sero status may encourages HIV sero positive clients to disclose their HIV sero status for the purpose of preventing HIV transmission and to support each other. In this study urban dwellers were nearly two times more likely to disclose their HIV sero status to their partner as compared to rural dwellers. This could be explained by the fact that, urban dwellers might get adequate HIV related information and care and support services. The other possible explanation may also be due to socio economic differences between urban and rural dwellers.

\section{Conclusion}

The level of HIV sero-status disclosure to sexual partners among adult HIV positive clients was low when compared with other findings in Ethiopia. The main reasons for non-disclosure among those participants who did not disclose their HIV positive status to their sexual partners were fear of stigma and discrimination followed by fear of partner violence. Disclosure of HIV sero status to sexual partner was significantly associated with clients' place of residence, receiving pre-test counselling related to disclosure and Knowledge of partners HIV sero status. Thus, to improve HIV sero status disclosure to sexual partner and overcome the mean reason for not disclosing, information education communication (IEC) interventions on HIV/AIDS should be strengthened particularly for rural dwellers. More emphasis should be given for mutual sexual partner HIV counselling and testing service. Provision of pre-test counselling regarding the benefit of disclosing HIV sero-status should be strengthens.

\section{Acknowledgements}

We would like to thank all study participants and data collectors for their role. Our special thanks also go to Bale health office as well as all study hospitals staffs and managers for their support during data collection.

\section{Author' Contributions}

We would like to declare that all authors involved in the work staring from inception of the research till to preparing the manuscript for publication.

\section{Conflict of Interest}

The authors declare that there is no conflict of interest with this research article.

\section{References}

[1] UNAIDS (2016) Estimate Global AIDS Progress Reporting (GARPR) from the Dis- 
trict Health Office.

[2] WHO (2000) Opening up the HIV/AIDS Epidemic. Guidance on Encouraging Beneficial Disclosure. Ethical Partner Counselling and Appropriate Use of HIV Case Reporting.

[3] WHO (2004) Gender Dimensions of HIV Status Discourse to Sexual Partners: Rates, Barriers \& Outcomes: A Review Paper. WHO. Geneva.

[4] World Health Organization (2003) Gender Dimension of HIV Status Disclosure to Sexual Partners: Rates, Barriers, and Outcomes for Women.

[5] Mwanga, J.A. (2012) HIV Sero Status Disclosure and Associated Factors among People Living with HIV/AIDS Attending a Care and Treatment Centre in Kisarawe District Hospital, Coastal Region, Tanzania.

[6] Naigino, et al. (2017) HIV Status Disclosure and Associated Outcomes among Pregnant Women Enrolled in Antiretroviral Therapy in Uganda: A Mixed Methods Study. Reproductive Health, 14, 107. https://doi.org/10.1186/s12978-017-0367-5

[7] Dankoli, R.S., et al. (2014) HIV Disclosure Status and Factors among Adult HIV Positive Patients in a Secondary Health Facility in North-Eastern Nigeria. Pan African Medical Journal, 18, 4. https://doi.org/10.11604/pamj.supp.2014.18.1.3551

[8] Medle, A., et al. (2013) Disclosure, Knowledge of Partner Status, and Condom Use among HIV-Positive Patients Attending Clinical Care in Tanzania, Kenya, and Namibia.

[9] Yaya, I. (2015) HIV Status Disclosure to Sexual Partners, among People Livingwith HIV and AIDS on Antiretroviral Therapy at Sokodé Regional Hospital, Togo. PLoS ONE, 10, e0118157.

[10] Alema, H.B., et al. (2015) HIV Positive Status Disclosure and Associated Factors among HIV Positive Adults in Axum Health Facilities, Tigray, Northern Ethiopia. Science Journal of Public Health, 3, 61-66.

[11] Deribe, K., et al. (2008) Disclosure Experience and Associated Factors among HIV Positive Men and Women Clinical Service Users in Southwest Ethiopia. BMC Public Health. https://doi.org/10.1186/1471-2458-8-81

[12] Seid, M., Wasie, B. and Admassu, M. (2012) Disclosure of HIV Positive Result to a Sexual Partner among Adult Clinical Service Users in Kemissie District, North East Ethiopia.

[13] Gari, T., Habte, D. and Markos, E. (2010) HIV Positive Status Disclosure Sexual Partner among Women Attending ART Clinic at Hawassa University Referral Hospital, SNNPR, Ethiopia. Ethiopian Journal of Health Development, 24.

[14] Tadese, A., Berihun, M. and Mamo, W. (2012) Predictors of HIV Status Disclosure to Sexual Partners among People Living with HIV/AIDS in Ethiopia. Pan African Medical Journal, 13.

[15] Genet, et al. (2015) Disclosure of HIV Seropositive Status to Sexual Partners and Its Associated Factors among Patients Attending Antiretroviral Treatment Clinic Follow up at Mekelle Hospital, Ethiopia: A Cross Sectional Study. BMC Research Notes, 8, 109. https://doi.org/10.1186/s13104-015-1056-5

[16] Bale Zone Central Statistical Agency Branch Office (2016) Population Projection.

[17] Bale Zone Health Office (2016) Health Management Information Report.

[18] Alemayehu, et al. (2014) HIV Disclosure to Sexual Partner and Associated Factors among Women Attending ART Clinic at Mekelle Hospital, Northern Ethiopia. BMC Public Health, 14, 746. https://doi.org/10.1186/1471-2458-14-746 